\title{
Integration of Heat Pumps in Distribution Grids: Economic Motivation for Grid Control
}

\author{
S. Nykamp, A. Molderink, V. Bakker, \\ H.A. Toersche, J.L. Hurink and G.J.M. Smit, Member IEEE
}

\begin{abstract}
Electric heat pumps combined with heat buffers are important elements in smart grids since they together allow to shift the consumption of electricity in time. In this paper the effects of different control algorithms for heat pumps on the investment costs for distribution grids are investigated. For this, an optimization approach is implemented for a case study within an area where the buildings are only supplied by electricity. The simulations use real smart meter data to generate realistic load curves of households and heat pumps. The calculations show that grid costs increase up to $71 \%$ with an inappropriate control and decrease by $10 \%$ with an optimal integration of heat pumps. Furthermore, the costs for the reinforcement of the grid are confronted with the benefits on consumer side using flexible price signals. The cost-benefit analysis shows that considering grid restrictions in the context of controllable devices is highly recommended.
\end{abstract}

Index Terms-- Cost benefit analysis, load management, heat pumps, heating, power distribution, power system planning, smart grids.

\section{INTRODUCTION}

$\mathrm{D}$ istribution grid operators are faced with changing requirements on grid performance and efficiency. An important challenge is the connection and operation of new types of 'controllable' consumption devices. These new appliances include electric cars, electric heat pumps and 'smart' white goods - all suitable in various forms for demand side management (DSM). The implementation of DSM is one element in the framework of smart grids, which may help to increase the amount of renewable energy systems and to raise efficient usage of grid assets.

Electric heat pumps experienced significant growth rates and have obtained a relevant share of heat supply systems. In Germany, the share of installation in new houses rose from $0.8 \%$ in 2000 up to $23.4 \%$ in 2010 . This development was accompanied by a corresponding decrease of the market share for natural gas heat appliances [1]. In the Netherlands, Gorinchem is an (and the first) area supplying all of the residential heat with heat pumps [2]. In Sweden and Switzerland, market penetration is even a lot higher, as described in [3]. The market share of ground-source heat pumps (GSHP) in new houses reaches $75 \%$ in Switzerland; in

S. Nykamp is with the network planning division of RWE Germany and the University of Twente; stefan.nykamp@rwe.com, s.nykamp@utwente.nl.

A. Molderink, V. Bakker, H.A. Toersche, J.L. Hurink and G.J.M. Smit are with the Faculty of Computer Science, Mathematics and Electrical Engineering, University of Twente, P.O. Box 217, 7500 AE, Enschede, the Netherlands; \{a.molderink,v.bakker,h.a.toersche,j.l.hurink,g.j.m.smit\}@utwente.nl. the Swedish renovation and modernization segment this value is even a bit higher. Also the USA as the world's largest market for GSHP has experienced a substantial increased market penetration of GSHP [3].

Heat pumps can play an important role in smart grids in the future. Since they are often equipped with hot water tanks and connected to an inert floor heating system, the consumption of power demand for the pump can be shifted in time. This flexibility can avoid bottleneck situations in the grid and help improving the integration of fluctuating power generation resulting especially from renewable energy sources. However, the steering of heat pumps using price signals can cause problems in local distribution grids since the assets of the distribution grid may not be dimensioned for large consumption peaks resulting from similar behaviour of the heat pumps caused by price steering signals.

We investigate the integration of electric heat pumps focusing on the grid costs in the low voltage level up to the next transformer. For this, we combine an optimization approach with concrete measurements of smart meter data for heat pumps and households. More precisely, for a concrete development area the grid costs are investigated by dimensioning the network of that area for different design values per household. The used design value is given by the maximum demand, which the grid operator takes into account for one connection point (household with heat pump). Hereby the grid operator assumes a non-synchronised consumption pattern with stochastic behaviour in the supplied area. We derive the design value resulting for three different cases which are a) flattening the consumption profile (peak shaving), b) the existing situation with static curtailing of the turn-off times of the heat pumps and c) the cost reduction on consumer side by using price signals. It is shown that grid costs differ depending on the design value and, thus, the optimization objective. The potentials for the cost reductions derived from these scenarios reveal conflicting interests. In the situation of peak shaving as the 'grid friendly' approach a cost reduction can be achieved for the grid operator and - with delay - for the consumer ('indirect' benefit, see e.g. [4]-[5]). In the scenario of using price signals, the consumer can directly reduce the costs for the consumption by using low price periods on the electricity spot market. However, grid costs increase significantly since in this case larger design values are needed and lead to additional and stronger dimensioned grid assets.

The remainder of this paper is organized as follows: in the next section we give a short overview on the current state of development. In Section III we present the optimization 
approach and results from some basic simulations. Section IV contains the results of a smart meter project, which determines the current design principles in new grid areas of a specific distribution grid operator. Furthermore, some statistical facts for the heat pump and household consumption are derived. These elaborations are used as basic input in Section V, where simulations for grid planning and investment costs are presented to show the influence of the different optimization approaches. To achieve the results, we use a specific development area embedded in a case study. The second part of this Section V presents a cost-benefit-analysis. We confront the additional grid costs in case of optimization on the consumer side with the (possible) cost reductions using periods with lower electricity prices. This welfare-economic view allows us to evaluate the potential of the full exploitation of DSM of heat pumps without considering grid restrictions. Hence, the results are derived for the specific, considered area, but the resulting trends for the costs and benefits are comparable in other electrified regions and countries. The analysis shows that the grid constraints should be taken into account to avoid an overcompensation of costs. This overcompensation is the case if additional grid costs exceed the cost reduction by DSM-operation and hence, welfareeconomic undesired situations occur. We end up in Section VI with some concluding remarks.

\section{RELATED WORK}

Heat pumps are seen as an essential element in the context of smart grids. Their functionality provides flexibility for grid operators, suppliers and consumers. Nevertheless, the (relatively high) connected load can lead to problems for grid assets. The increasing complexity in distribution grids is discussed in [6]. According to the study, smart grids are a possible solution to cope with the challenges resulting from more distributed generation by PV panels, wind turbines and micro-CHPs. This may be achieved with improved monitoring and control of grid assets and generators. But how the different market roles (like grid operator, supplier and metering service provider) should cooperate to achieve an improvement and introduce more generation in a smarter way, is not explained. In [7] the view of the network operator is described. The benefits of smart grid technologies are listed as increasing reliability, flexibility and efficiency. It is stated that the term 'smart grid' is used as an umbrella for alternative technologies to traditional methods for network operation. Furthermore, a few pilots from various countries (e.g. demand response and storage projects) are described that helped achieving the mentioned benefits. The classification as 'pilot projects' of these examples gives a clue to the massive efforts necessary to exploit the smart grid potential which is evaluated in [8]. Their investigations focus on the US grid and estimate the costs for implementing a far-reaching version of a smart grid up to 476 billion US\$ leading to benefits of up to 2,000 billion US\$.

For the technology of heat pumps and their role in smart grids also an abundant amount of literature exists. A heat pump consumes electricity to raise an operating medium (OM) from a lower to a higher temperature level. The OM changes the thermodynamic state within the process. In liquid form, it withdraws evaporation heat from the heat source and becomes gaseous. The pump compresses the OM so that temperature is raised and heat can be transmitted to the heating circuits. The OM liquefies during cooling and the cycle gets closed. The main used heat sources are soil (ground), air and water. Soilwater heat pumps extract the energy using horizontal collectors or geothermal probes. Air-water pumps work with the outside air and are therefore faced with more fluctuating temperatures in the heat source. The water-water heat pumps use the temperature of surface water and ground water. A more detailed description of the heat pump technology and current developments can be found in [9], where also different studies are joined to show fields of applications. Furthermore, [10] gives an overview on the history and ecological advantages of heat pumps.

In an energy hub model [11], the heat pump is included as an active part within the energy network model. The focus of the energy hub model is on evaluating the profitability of heat load management on the consumer side. By considering changing spot market prices, the heat pump can be managed to avoid peak prices and instead operate in off-peak-periods. The simulations show a potential cost reduction of more than $10 \%$ for the consumer. Restrictions from grid side are not considered. The analysis in [2] focuses on the potential of smart control from the perspective of the grid operator. It is shown that a smart control can avoid exceeding the maximum permitted load values of the transformer in a substation in the distribution grid. The opposite is shown for uncontrolled scenarios in case of autonomous starts after a blackout. In this scenario, the operation of the heat pumps would lead to three times higher load values than permitted.

To analyse resulting grid costs with different optimization objectives, we use an approach developed at the University Twente. This method is described in a short summary in the next section.

\section{OPTIMIZATION POTENTIAL}

The potential of demand side management and resulting energy streams can be controlled and analysed using the three step optimisation methodology TRIANA developed at the University of Twente [12]. The approach consists of 1) offline local prediction of energy profiles, 2) offline global planning of energy streams and 3) online local scheduling of appliances in individual buildings. In the first step, the production and consumption profiles for all relevant devices of the household are predicted. The energy profile includes historical usage pattern as well as external factors like the weather. The optimization potential of the household, derived from these predictions, is used in the second step by a central planner to reach a global objective. Examples for the objectives are peak shaving or compensation for the fluctuation resulting from energy generation out of renewable energies, but also the maximization of margins on the consumer side may be an objective. In the latter case, the consumer may shift consumption of the devices like a heat pump to time periods with low prices to reduce his costs. The third step is responsible for the real-time control using steering signals. Thereby, the planning of the second step is taken as input and the control tries to follow the production pattern of the planning as close as possible, but the comfort of the residents in conflict situations stays leading (for detailed see [12] and 
[13]). The control strategy is flexible in the optimization objective and works in a generic way. The effects of the optimization methodology are modelled and verified with a simulator [14].

In [15] it is described how the heat pump with its specific characteristics can be integrated in the three step methodology. As objective for the optimization within the control problem peak shaving is used. Furthermore, in [15] a use case with 100 houses is considered and the results of simulations prove a significant decrease in peak consumption by using TRIANA. The impact of the steering mechanism is shown in Fig. 1. The load curve visualizes the decreased peak and the more uniform distribution of demand and the flattened profile. This effect is visible in the hours with low demand, too. Without steering signals, certain time periods have no demand - the potential of heat pumps for shifting demand is unused.

The simulations show a considerable decrease of the peak and an improved and flattened consumption profile. The peaks decrease by $25 \%$ and the variation of the load by $33 \%$. Furthermore, we expect that by refining the control (e.g. with improved planning) even more potential can be shown.

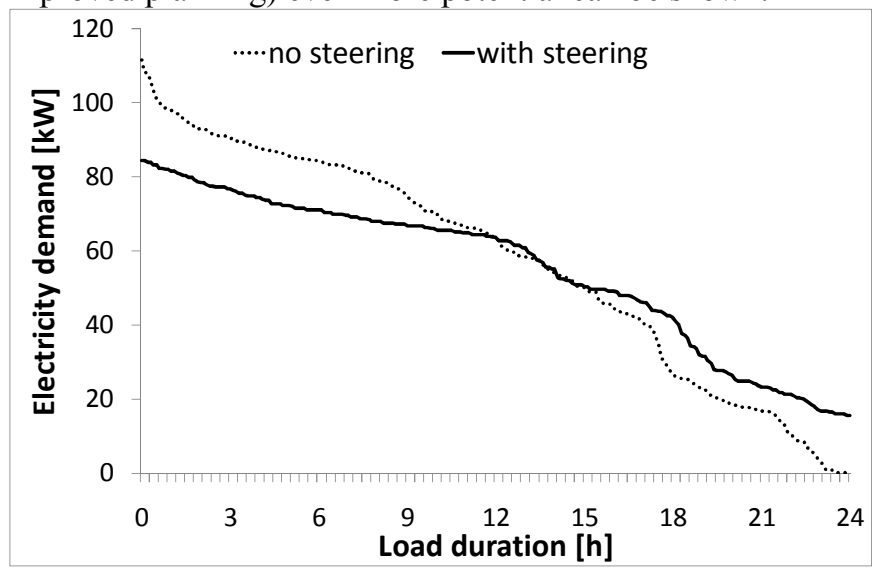

Fig. 1. Optimization of heat pumps (peak shaving), see [15]

\section{SMART METER PROJECT}

In this section we give some results of a smart meter project. The obtained metering data allows further analysis of the consumption of households and heat pumps. In addition to the control methodology described in the previous section, these realistic data are relevant parameters for the case study in Section V.

For a group of 10 new houses in the region of Neuenhaus, Germany, 20 smart meters were installed, each measuring the electric consumption of heat pump and (rest of the) household separately. This pilot project was conducted to test a specific kind of smart meter technology and analyze data of (new) households and soil-water heat pumps. Furthermore, weather data of a nearby weather station is available. The smart meter data was measured and transmitted at a 15 minutes interval, the weather data with 10 minutes intervals. The duration of the project was eight weeks in a winter with a minimum measured outside temperature of $-8.0^{\circ} \mathrm{C}$.

The heat pumps are equipped with a separate meter since it is the intention to use the heat pump as an adjustable consuming device. The grid operator is authorized by contract to switch off the heat pump in case of (other) high consumption peaks in the grid to avoid overload. In particular, the turn-off times of the heat pumps are determined such that it can reduce or even avoid an increase of the consumption peak per household due to the use of heat pumps. During peak times when the pumps are switched off, all heat demand should be supplied using the heat buffer. This hot water tank in combination with a slow response floor heating system avoids a loss in comfort for the consumer. This installation setup was realized in all of the 10 houses, the heat buffer was typically dimensioned at 200-300 1. Currently, the demand of the heat pumps is statically curtailed for two hours at noon. The turn-off time is based on historically measured values of household peaks and can be changed, e.g. to three times per day for one hour.

The houses are heterogeneous and highly insulated considering currently implemented standards that are prescribed by the German law [16]. The heat pumps have a maximum power demand of 2 to $5 \mathrm{kVA}$. The minimal allowed efficiency for heat pumps is regulated by law too [17] - for soil-water heat pumps in new houses with hot water heating the annual coefficient of performance (aCOP or seasonal performance factor, see for more detail [18]) has to be at minimum 3.8. The normal market standards according to manufacturers' data are between 4 and 5. In [19], even a COP of 6 has been evidenced. ${ }^{1}$ In addition to the heat pump, houses have an axiliary heating rod of 5 to $10 \mathrm{kVA}($ 'COP' $<1)$.

Using the heating rod for supplying all heat demand is prohibitively expensive for the customer. Furthermore, it can cause grid problems if all houses operate at the same time with the heating rod. The heating rod is therefore exclusively enabled as a backup in case the heat pump system is malfunctioning. In our measurement data, this occurred for one day at one house (causing approximately $15 €$ in electricity consumption for the household). It is essential that the diversity factor (defined as the quotient of the actual used and the installed capacity) of the heating rod is very low, i.e. nearly all houses must not rely on it to avoid overload of the grid assets. To exclude the working of the heating rod (and the high costs), six of the ten households even disconnected the heating rod without having problems in winter due to the high insulation standards.

In the chosen grid area, the network is planned with a design value for a house (including heat pump) of $3.5 \mathrm{kVA}$ each. This value is based on the consideration that not all heat pumps and households consume electricity at the same time with their maximum connected load. Moreover, the experiences gained from other areas regarding the different used heat sources are incorporated. Consumers use alternatively natural gas appliances (more and more with support of solar collectors), district heating with biomass combustion or wood pellet heating [1]. This goes along with legal requirements - in Germany (as the measured data are determined from here), the usage of a renewable heat sources for heat supply in new houses is prescribed per law [17].

Summarizing, it can be stated that the design demand of 3.5 $\mathrm{kVA}$ is based on historical measured and calculated values. It

\footnotetext{
${ }^{1}$ It has to be clarified, that the maximum COP is a kind of 'snapshot'. The value massively depends on the temperature of the heat source and the water in the heating cycle (heat sink). Thus, the COP has to be described with underlying parameters (temperature level) or to be oriented to an appropriate period of time (e.g. one year).
} 
increased within the years considering the increasing demand in households and the increasing installation of heat pumps. However, a complete supply of heat in an area with only heat pumps operating has not been taken into account yet.

To give a first impression on the measured data, we visualize the load curve of the demand for electricity for the average heat pump and household in Fig. 2. For one specific day, the curves show the average demands of the heat pumps (HP) and the separately measured remaining appliances of the household $(\mathrm{AHH})$ as well as the sum of both values. Note, that the chosen day is the day with the maximum measured load value of $3.74 \mathrm{kVA}$ since the grid has to be designed for this worst case. The load curve of HP is most of the time above the load curve of AHH. Exceptions are hours in the evening (due to increased household consumption) and noon (due to turnoff time of the heat pump). As described earlier, the turn-off time in these midday hours is based on historical consumption patterns. As can be seen in this figure, the peak of $\mathrm{AHH}$ is significantly more pronounced in the evening. This is confirmed by the measurement of the other days in this winter time considered. The visualized day on the one hand shows the general trends and, on the other hand, contains the only time within the complete measured period where the aggregated load curve exceeded the $3.5 \mathrm{kVA}$ line. The exceeding of this currently defined design value is measured at 8 p.m. with a temperature of $-0.2{ }^{\circ} \mathrm{C}$. Since grid structures have to be built for the worst-case scenario, the maximum value has to be considered when determining the design value for the consumption of households with heat pumps.

Besides the visualization of $\mathrm{HP}$ and $\mathrm{AHH}$ we can deepen the analysis to reveal more statistical correlations within the data set of the complete measured period. ${ }^{2}$

A further analysis shows that the line for HP decreases in process of time. This effect results from the increasing outdoor temperature. We calculate the correlation coefficient $r$

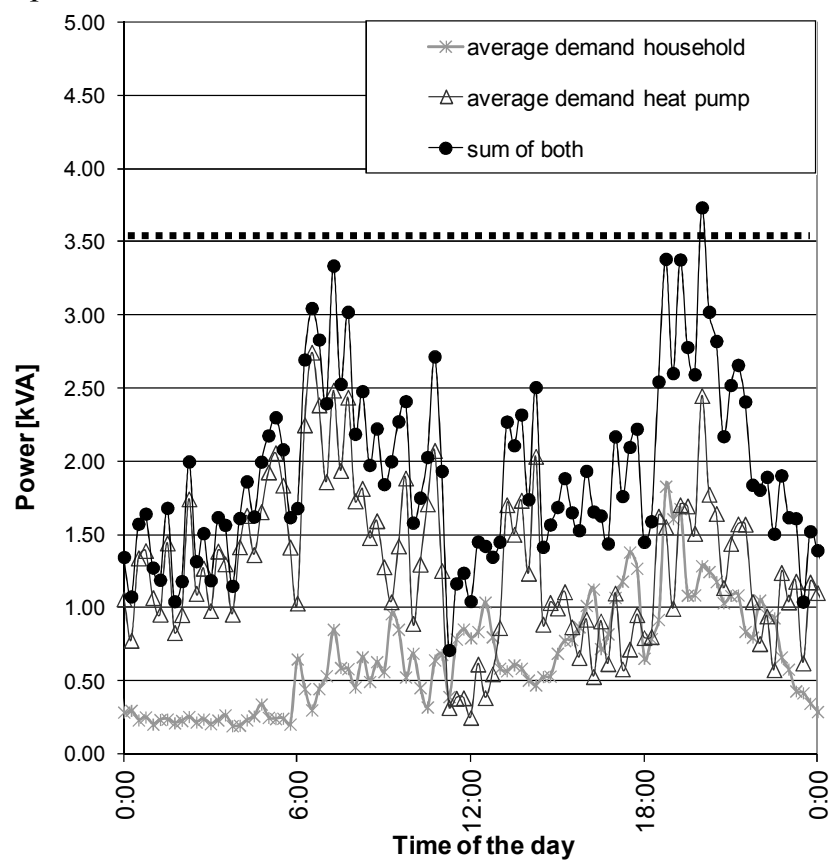

Fig. 2. Smart meter results with highest load values

\footnotetext{
${ }^{2}$ Considering the data for weather, $\mathrm{HP}$ and $\mathrm{AHH}$, the data set consists of more than 100.000 values.
}

between HP (X) and outdoor temperature T (Y). For our data set, we get $r_{X, Y}=-0.534$.

The strong negative correlation was to be expected since an increase of $\mathrm{T}$ leads to less requirements for heat and therefore to a lower demand of heat pump power. If the correlation coefficient would reach a value of -1.0 , a perfect negative correlation would be shown. This value is in real life unrealistic due to inertia of the heat pump system and connected buffer capacities as well as influences in consumption behaviour.

Furthermore, the correlation between the demand of households and heat pumps is analyzed. It is preferable that this value is negative as well to prevent a situation where the peaks in demand intensify each other. With a positive correlation coefficient the heat pump would not behave 'grid friendly'. In this case, the peaks in the consumption pattern would even become larger since peaks of household and heat pump behave additive. We calculate the correlation coefficient $\mathrm{r}$ between heat pump demand $\mathrm{X}$ and demand of household $\mathrm{Y}$ and get $r_{X, Y}=-0.018$. This indicates that no statistical dependence is detectable. In addition, a view on the load curves shows the necessity of changing the turn-off times since the peaks in the households curve appear mainly in the evening hours and, thus, the turn-off time of the heat pump should be changed to this period to reduce instead of increase the consumption peaks. This improvement should become visible by a more pronounced negative value of the correlation coefficient. The design value in grids can be left unchanged even if - as assumed in the case study - a penetration of $100 \%$ heat pumps as heat supply system for the households is reached. The consumers would not be affected by changed turn-off times since comfort would not be sacrificed due to the (time-modified) usage of the existing buffer capacities and the inertia of floor heating.

For new houses in the considered grid, the design value is still projected with $3.5 \mathrm{kVA}$, based on better interior insulation (decreasing heat and therefore also electricity demand). Furthermore, the turn-off time in new areas has been changed to be effective in gradual form and including especially the evening hours now. This result was the first consequence of our measurements. The correlation coefficients gave further information supporting the decisions. For the further analysis, we define this scenario with the current design value as 'state of the art'. A more smart and dynamic approach of steering heat pumps will be implemented in the future.

Considering the connected loads and the current design value, the need of a balanced control becomes visible - the average nominal capacity of the connected heat pumps amounts to $3.95 \mathrm{kVA}$ and the maximum household peak was measured at $1.94 \mathrm{kVA}$ per household. This sum of $5.9 \mathrm{kVA}$ is the 'worst case' design value since it is the highest value, which might occur. Note that this excludes the power of the heating rod since almost all houses disconnect this appliance nowadays. The value of $5.9 \mathrm{kVA}$ is much higher than the measured results and derived values for the optimized integration of heat pumps. It has to be considered as design value in case of price steering due to the same reactions on price signals (see, for example [20] for an analysis of the diversity factor of adjustable devices). At a large scale, this results in excessive infrastructure investment and higher 
maintenance costs. These increased capacities are only used when all houses and heat pumps simultaneously reach their maximum value. However, this is rarely the case and leads to inefficient usage of the (in the rest of the year) oversized grid assets.

In contrast and as mentioned in Section III a peak reduction of $25 \%$ can be achieved using the control approach TRIANA. Combining this with the measured data, this would lead to a decreased design value of $3.0 \mathrm{kVA}$ (for households with heat pumps). Hence, we use this value as the design value for the scenario of grid optimal introduction of heat pumps.

Both values, the $3.0 \mathrm{kVA}$ for optimal integration and the 5.9 kVA for the 'worst case', are considered in the case study in the next section. In detail, we include the theoretical and practical results of this and the previous section in a calculation of the grid costs for various scenarios. The purpose of this case study is to identify how different steering methods and objectives for heat pumps affect the investment costs in the distribution grid.

\section{CASE STUdy}

The case study is divided into two parts. In the first part, the effects of different design values on the network planning and exploitation are shown. The measured data (Section IV) can be combined with the values from the simulations in Section III. The different design values lead to different investment costs for the exploitation of an area with electricity. The second part includes a short estimation of the cost-benefitratio for using the full potential of demand side management of the heat pumps.

\section{A. Scenarios for Grid Dimensioning}

The case study analyses grid costs in an area, where all residential heat will be supplied with heat pumps. Since our measurement data originates from soil-water heat pumps, we assume this technology to provide all heat for the households. If another heat source would supply all of the heat (e.g. airwater heat pumps), a changed design value may be possible due to other operating modes and power demands. Nevertheless, the trends in grid costs for the different scenarios should be comparable.

The difference of the design value of houses with heat pumps has massive impact on the number and dimension of grid assets (e.g. cables, transformers). For the various scenarios, we evaluate the investment costs for supplying the area with electricity. Hereby, the investment costs reflect the annual capital expenditures (CAPEX) as an important part of the costs of grid operators (for more details see [21] and further elaborations in the remainder of this section). We distinguish between new and existing areas since especially costs for underground digging are much higher in existing areas with tarred or paved surfaces (e.g. roads).

The main restrictions in the planning process of distribution grids are a) stress of assets and b) voltage values. Each asset has an individual value for permissible stress - e.g. for cables and transformers maximum power transfer is restricted by asset specific current values (ampacity). Furthermore, a higher load can cause the voltage to fall below the minimum permitted voltage of public supply. These limits are determined in the European norm EN 50160 [22]. The most important is the voltage magnitude variation requiring a supply within $\pm 10 \%$ of the nominal voltage.

Considering these restrictions we plan the electricity supply for an example area with 102 households. The chosen area was opened in 2010 and the first houses have been connected to the grid, so we have realistic and up to date values for the investments, the possible routes for cables and positions for transformers. In the current network planning, one substation is intended to supply the area. The connected low voltage cables are operating as three-phase current cables with $400 \mathrm{~V}$, the medium voltage cables connected to the transformer work with $10 \mathrm{kV}$. The network planning and calculation for voltage and stress values is made with proprietary programs used by grid operators in Germany. This applies for the estimation of the costs for the investments, too.

As mentioned in the previous sections, we investigate the effects of three different design values for a connection point (household including heat pump) in four scenarios:

(a) $3.0 \mathrm{kVA}$; this value is possible if optimization of the use of heat pumps is applied (peak shaving).

(b) $3.5 \mathrm{kVA}$; this value is possible with changed turn-off times of heat pumps, but no further control ('state of the art').

(c) $5.9 \mathrm{kVA}$; worst case scenario if all heat pumps consume electricity simultaneously with the nominal capacity as maximum possible load but without heating rod (e.g. based on price signals).

(d) like c (5.9 kVA), but simulated in an already existing area, where the grid structure previously has not been dimensioned for this (relatively) large design value.

Note, that the following derived results for the numbers of assets and, thus, for the investment costs depend heavily on the situation of the chosen supply area. However, the general approach and the elaborations apply also for other distribution grid areas. The differences in grid structures and in the number and dimension of assets for the considered area are shown in Fig. 3. Thereby, the low voltage level is characterized by the different low voltage circuits supplying the area with each circuit having a limited capacity. Thus, a limited number of houses can be connected to a circuit. We visualize the allocation of households to the different low voltage circuits in Fig. 3. The single low voltage systems are illustrated with different symbols supplying the allocated houses. As expected a larger design value for a household leads to a smaller number of households per cable and therefore a larger number of circuits to supply the area with electricity.

In existing areas a further spread of heat pumps can require an increase of the design value, so grid assets must be adapted to the new situation. Historically, such a grid was not dimensioned for the high consumption peaks in all households. In existing areas, the costs per meter of ditch are significantly higher compared with new areas as CAPEX increases with solid surfaces. These effects have to be considered in the costs calculation as well. Therefore, in this fourth scenario (d), new cables for the reinforcement have to be installed and connected to existing ones - the households have to be reallocated to the circuits due to the increased design value to avoid impermissible stress and voltage values. The allocation of households in this scenario (d) complies with scenario (c) in Fig. 3. 


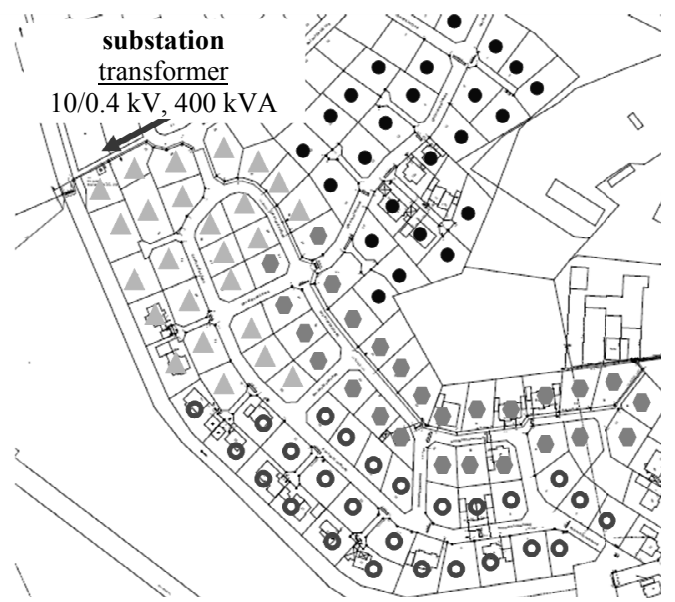

a) design value of $3.0 \mathrm{kVA}$ per household

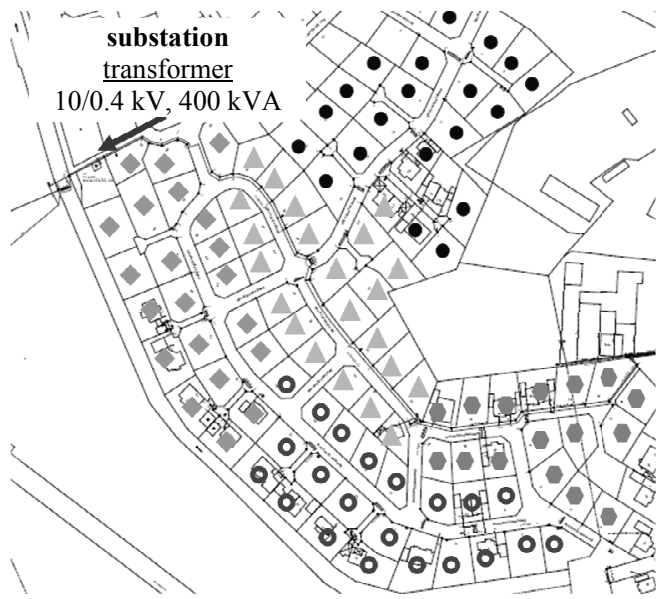

b) design value of $3.5 \mathrm{kVA}$ per household

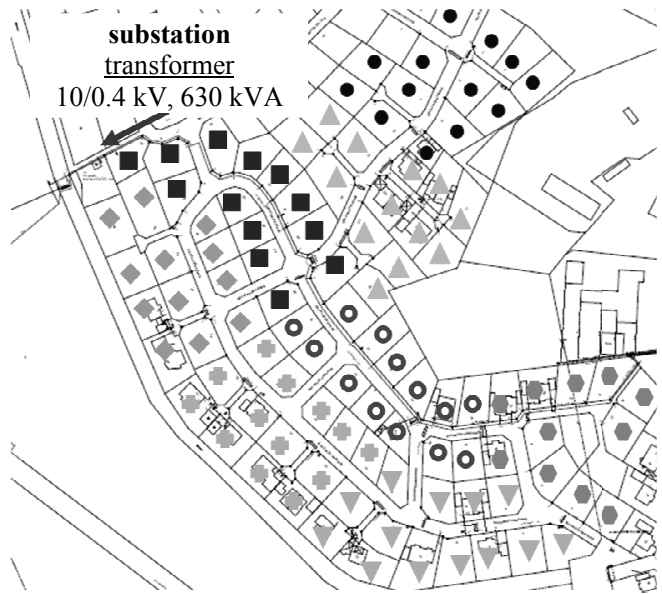

c) design value of $5.9 \mathrm{kVA}$ per household

Fig. 3 Allocation of houses depending on the design value

The resulting values for circuits, transformers, cables and ditches for the different scenarios are given in Table 1. Furthermore, the estimated costs of the different scenarios (CAPEX) are presented. For this, we set the costs for the 'state of the art' exploitation (scenario (b)) as 100\% and report the differences of the other scenarios to these costs.

One main result is that the number of power circuits increases with a larger design value leading to increased number of cable-meters but hardly increased number of ditch- meter. This seems to be reasonable since the size of the supplied area as the main influencing factor of the length of ditches is not influenced. Regarding scenario (d) the length increases because of the new ditches which have to be dug next to the existing ones for the connection of new cables to the transformer and reallocation of households. Furthermore, the more solid surfaces raise the costs significantly.

It can be concluded that an optimal integration of heat pumps leads to a cost decrease of $10 \%$ in comparison to the state of the art. A full exploitation of DSM and therefore of maximum power of heat pumps leads to a massive cost increase. In new areas, this investment is $22 \%$ higher than in the basic scenario; in existing areas this value rises up to $71 \%$. Table 1:

Costs and asset numbers for the different scenarios

\begin{tabular}{|l|c|c|c|c|}
\hline \multicolumn{1}{|c|}{ Scenario } & $\begin{array}{c}\text { a) peak } \\
\text { shaving }\end{array}$ & $\begin{array}{c}\text { b) state of } \\
\text { the art }\end{array}$ & $\begin{array}{c}\text { c) maximum } \\
\text { DSM of HP } \\
\text { in new } \\
\text { areas }\end{array}$ & $\begin{array}{c}\text { d) maximum } \\
\text { DSM of HP } \\
\text { in existing } \\
\text { areas }\end{array}$ \\
\hline $\begin{array}{l}\text { design value per } \\
\text { household [kVA] }\end{array}$ & 3.0 & 3.5 & 5.9 & 5.9 \\
\hline $\begin{array}{l}\text { power circuits } \\
\text { [number] }\end{array}$ & 4 & 5 & 8 & 8 \\
\hline $\begin{array}{l}\text { size of } \\
\text { transformator } \\
\text { [kVA] }\end{array}$ & 400 & 400 & 630 & 630 \\
\hline $\begin{array}{l}\text { meters of cable } \\
\text { [m] }\end{array}$ & 2,315 & 2,765 & 3,735 & 3,800 \\
\hline $\begin{array}{l}\text { meters of ditch } \\
\text { [m] }\end{array}$ & 1,575 & 1,685 & 1,715 & 2,340 \\
\hline CAPEX [\%] & $\mathbf{9 0}$ & $\mathbf{1 0 0}$ & $\mathbf{1 2 2}$ & $\mathbf{1 7 1}$ \\
\hline
\end{tabular}

\section{B. Cost-Benefit Ratio}

In the following we set up an initial estimation on the costbenefit ratio. This ratio visualizes the relation between increased investment costs for the grid and the attributed cost reductions on the consumer side. The direct attribution is possible since the reinforcements are only necessary to allow the full exploitation of demand side management of heat pumps.

First, we visualize the economic benefit with the payback period. Thus, the main question is if and when the additional investments costs are amortized by the annual cost reductions. This welfare-economic approach opposes the CAPEX on grid side with the cost reductions on consumer side. The increased CAPEX will result in higher grid fees for the consumers, so the economic calculation should show positive results in the interest of all market participants. To calculate the consumer benefits, we use the following parameters:

- saved electricity costs for the consumer per $\mathrm{kWh}$ : $\mathrm{p}=-3 \mathrm{ct} / \mathrm{kWh}^{3}$

- duration of the consumption peaks in the grid due to low price phases : $\mathrm{t}=200 \mathrm{~h} /$ year

- number of relevant heat pumps: $n=102$

- available heat pump power (each): $\mathrm{P}=2 \mathrm{~kW}$.

These parameters are verified with the spot market prices for electricity in Germany. In 2010, the average hourly price

\footnotetext{
${ }^{3}$ It has to be noticed, that the fixed parts of the electricity price for the consumer remain (such as taxes).
} 
on the EPEX auction market is given by $4.449 \mathrm{ct} / \mathrm{kWh}$. We find 257 hours with a price at least $3 \mathrm{ct} / \mathrm{kWh}$ below the average value. In 68 hours, we find an hourly price at least 4 $\mathrm{ct} / \mathrm{kWh}$ below the average value. In 12 hours in 2010, even negative prices are given. Since the heat pump only works reasonably in cases of demand for heat or cooling, our assumptions seem to be comprehensible.

Using the above parameters, we get for the sum $\mathrm{C}$ of the cost reductions on consumer side:

$$
\mathrm{C}=\mathrm{p} \cdot \mathrm{t} \cdot \mathrm{n} \cdot \mathrm{P}=3 \frac{\mathrm{ct}}{\mathrm{kWh}} \cdot 200 \frac{\mathrm{h}}{\text { year }} \cdot 102 \cdot 2 \mathrm{~kW}=1,224 \frac{€}{\text { year }}
$$

Comparing this with the needed additional costs for the investments (scenario (c) and (d)) we can calculate the (welfare-economic) payback period.

For this, we assume an interest rate of $6 \% /$ year to cover costs for financing and consider risks for investments. The cost savings start in the year 1 following on the investment in the year 0 and are given in Table 2. For scenario (c) we get a payback period of 68 years for the additional investments. In scenario (d) (high investments due to reinforcement and more expensive surfaces) we do not even achieve a payback period.

Table 2: Calculation of payback period

\begin{tabular}{|c|c|c|}
\hline year of cost saving & $\begin{array}{c}\text { annual amount } \\
\text { (discounted) [€] }\end{array}$ & cumulated amount [€] \\
\hline 1 & 1,155 & 1,155 \\
\hline 2 & 1,089 & 2,244 \\
\hline 3 & 1,028 & 3,272 \\
\hline 4 & 970 & 4,241 \\
\hline 5 & 915 & 5,156 \\
\hline$\ldots$ & $\ldots$ & $\ldots$ \\
\hline
\end{tabular}

In the above calculations, we neglect the fact that the heat pumps are installed gradually in the area and that increased grid costs may occur on higher voltage levels, too. This more realistic view would even increase the payback period. Furthermore, it should be mentioned that, currently, the reaction of consumption devices on price signals or on grid requirements to lower the load is not enabled on a large scale. This is mainly caused by the lack of smart meters, appropriate information and communication technologies and suitable products. The exploitation of this potential in the context of smart grids is an important task for the future and, thus, also a political objective.

To show the effects described above and in Table 2 in an alternative way, we calculate the cost-benefit ratio for scenario (c) and (d). If the investment is reasonable from a welfareeconomic point of view, the benefit should outweigh the costs and thus, the ratio should be smaller than 1 . To calculate the ratio, the annual costs (annuity) for the investment costs have to be determined. With the given investment, the interest rate and the lifetime of the grid assets, it is possible to calculate the CAPEX as annual costs. We assume for the low voltage cable a lifetime of 40 years as a typical value for this kind of asset (see for example [23]). For the cost-benefit-ratio the CAPEX as annual costs are compared with the annual cost savings on the consumer side. For scenario (c) we get a cost-benefit-ratio of 1.10. For scenario (d) this ratio increases up to 3.60 . Especially in the latter case, the costs significantly outweigh the benefits.
The above calculations do not dispute the profitability of demand side management - the meaningfulness should not be questioned at all, too. Instead, grid load management in the context of controllable appliances is required to avoid an overcompensation of cost reductions with DSM by massive higher CAPEX costs for the grid investments, even though costs and benefit may differ in other areas. Additional DSMtechnologies will strengthen this need for grid control since especially electric cars have much higher connected loads than heat pumps and can cause therefore even larger grid problems.

\section{CONCLUSION}

In this paper we investigated the effects of heat pump introduction on distribution grid structures. The results of the steering scenarios (peak shaving, demand side management (DSM)) in combination with realistic measured values lead to different design values of households with heat pumps and, thus, varying investment costs for the distribution grid. The scenarios of 1) optimal integration with peak shaving, 2) the current measured situation and 3) maximum exploitation of DSM potential and, thus, synchronized reaction on price signals, are compared in a case study. The decrease as well as the increase in grid costs is quantified depending on the optimization objective.

The results of the case study show that a full exploitation of DSM potential only based on price signals leads to extra costs on the grid side for additional and stronger dimensioned assets to cope with the consumption peaks of heat pumps. These costs can exceed the cost reduction on the consumer side enabled by using lower prices for the operation of the heat pumps. As a consequence, grid restrictions should be considered in smart grids to avoid welfare-economic unreasonable situations with overcompensation of costs in grids resulting from DSM. The simulations show that a decrease in local grid costs of $10 \%$ is possible if the optimization objective is oriented towards peak shaving. Thus, smart optimization approaches considering grid restrictions play a key role in the context of smart grids to reach global objectives with acceptable costs.

The investigation of additional DSM-technologies and the introduction of local power generation out of renewable sources in simulations as well as the partitioning of costs and benefits in the framework of smart grids over relevant stakeholders is left for future work.

\section{ACKNOWLEDGEMENT}

This research is conducted within the DREAM project supported by STW.

\section{REFERENCES}

[1] AG Energiebilanzen (2011). "Energieverbrauch in Deutschland, Daten für das 1. Quartal 2011.” [Online]. Available: http://www.agenergiebilanzen.de/viewpage.php?idpage=118, 2011.

[2] O. v. Pruissen and I. Kamphuis, "Grote concentraties warmtepompen in een woonwijk en gevolgen elektriciteitsnetwerk," ECN, Tech. Rep. ECN-E-10-088, 2010.

[3] W. Goetzler, R. Zogg, H. Lisle, J. Burgos, "Ground Source Heat Pumps: Overview of Market Status, Barriers to Adoption, and Options for Overcoming Barriers.” [Online]. Available: http://www1.eere.energy.gov/geothermal/publications.html, 2009 
[4] D. Bauknecht, "Incentive regulation and network innovations." EUI RSCAS; Loyola de Palacio Programme on Energy Policy, 2011.

[5] Nykamp, S., Andor, M., Hurink, J.L., "'Standard' incentive regulation hinders the integration of renewable energy generation". Energy policy (2012), DOI: http://dx.doi.org/10.1016/j.enpol.2012.04.061, 2012

[6] H. Slootweg, "Smart grids - the future or fantasy?," Smart Metering Making It Happen, 2009 IET, pp. 1-19, 19-19 Feb. 2009.

[7] V. Hamidi, K.S. Smith, R.C. Wilson, "Smart grid technology review within the Transmission and Distribution sector," Innovative Smart grid Technologies Conference Europe (ISGT Europe), 2010 IEEE PES, pp.1-8, 11-13 Oct. 2010

[8] Electric Power Research Institute (EPRI), "Estimating the Costs and Benefits of the Smart Grid." [Online]. Available: http://my.epri.com/portal/server.pt?space=CommunityPage\&cached=tru e\&parentname $=$ ObjMgr\&parentid $=2 \&$ control $=$ SetCommunity\&Commu nityID=405, 2011.

[9] K. Chua, S. Chou, and W. Yang, "Advances in heat pump systems: A review," Applied Energy, vol. 87, no. 12, pp. 3611-3624, 2010

[10] H.J Laue; "Regional report Europe: 'heat pumps - status and trends", International Journal of Refrigeration, Volume 25, Issue 4, Pages 414420, June 2002.

[11] P. Ahcin, and M. Sikić, "Simulating demand response and energy storage in energy distribution systems", Power System Technology (POWERCON), 2010 International Conference, pp.1-7, 24-28 Oct 2010.

[12] V. Bakker, M.G.C. Bosman, A. Molderink, J.L. Hurink, G.J.M. Smit, "Demand Side Load Management Using a Three Step Optimization Methodology," Smart grid Communications (SmartGridComm), 2010 First IEEE International Conference, pp.431-436, 4-6 Oct. 2010

[13] A. Molderink, V. Bakker, M. Bosman, J. L. Hurink, and G. J. M. Smit, "A three-step methodology to improve domestic energy efficiency," in IEEE PES Conference on Innovative Smart Grid Technologies, 2010.

[14] V. Bakker, A. Molderink, M. Bosman, J. L. Hurink, and G. J. M. Smit, "On simulating the effect on the energy efficiency of smart grid technologies," in Proceedings of the 2010 Winter Simulation Conference, 2010.

[15] H.A. Toersche, V. Bakker, A. Molderink, S. Nykamp, J. L. Hurink, and G. J. M. Smit, "Controlling the heating mode of heat pumps with the TRIANA three step methodology" in Proceedings of the 2012 IEEE PES Innovative Smart Grid Technologies (ISGT), 2012.

[16] Verordnung zur Änderung der Energieeinsparverordnung, 29.April 2009

[17] Gesetz zur Förderung Erneuerbarer Energien im Wärmebereich (Erneuerbare-Energien-Wärmegesetz - EEWärmeG), 2009.

[18] J. Lund, B. Sanner, L. Rybach, R. Curtis, G. Hellström, "Geothermal (ground source) heat pumps - a world overview," Geo-Heat Centre Quarterly (Klamath Falls, Oregon: Oregon Institute of Technology) 25 (3), 2009.

[19] P. Chaiwongsa, S. Wongwises, "Experimental study on R-134as refrigeration system using a two-phase ejector as an expansion device." Appl Therm Eng 2008; 28 (5-6): 467-477, 2008

[20] B. Gwisdorf, S. Stepanescu, C. Rehtanz, "Effects of Demand Side Management on the Planning and Operation of Distribution Grids." IEEE PES Conference on Innovative Smart Grid Technologies Europe, Göteborg, 10.-13.10.2010.

[21] B. Mountain, and S. Littlechild, "Comparing electricity distribution network revenues and costs in New South Wales, Great Britain and Victoria," Energy Policy, Volume 38, Issue 10, Pages 5770-5782, 2010

[22] DIN EN 50160:2010, Voltage characteristics of electricity supplied by public distribution networks, 2011.

[23] StromNEV, Bundesministerium der Justiz. Verordnung über die Entgelte für den Zugang $\mathrm{zu}$ Elektrizitätsversorgungsnetzen (Stromnetzentgeltverordnung - StromNEV), 2011.

\section{BIOGRAPHIES}

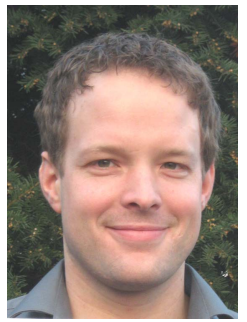

Stefan Nykamp was born in Nordhorn, Germany in 1983. He received his M.Sc. degree from the University of Muenster and the RWTH Aachen, Germany in 2010 in Energy Economics. Currently, he is a Ph.D. candidate at the University of Twente, Enschede, the Netherlands and works in the distribution network planning with RWE, Germany. His research interests include the technical and economic integration of renewable energy systems and the (appropriate) regulation of (smart) grids.

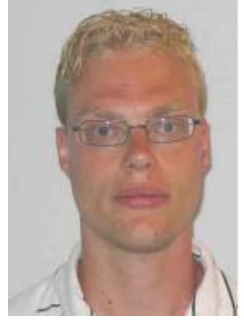

Albert Molderink received his B.Sc and M.Sc. degree in Computer Science from the University of Twente, Enschede, The Netherlands, in respectively 2004 and 2007. In 2011 he received his PhD degree from the same university. He is working in a research group that investigates the possibilities of increasing energy efficiency using embedded control, mainly via optimization and control algorithms. His research focus is on algorithms to optimize energy streams within a house.

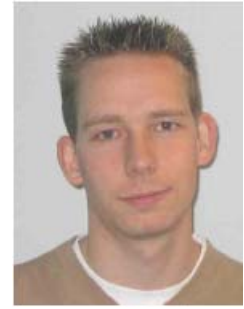

Vincent Bakker received his M.Sc. degree in Computer Science from the University of Twente in 2007, with a minor certificate in Entrepreneurship. In 2012 he received his Ph.D. degree on his thesis 'Triana: a control strategy for Smart Grids'. Currently he is continuing his research at the Computer Architectures for Embedded Systems group of the University of Twente. His research interests are machine learning, optimization modeling and large scale distributed (intelligent) systems.

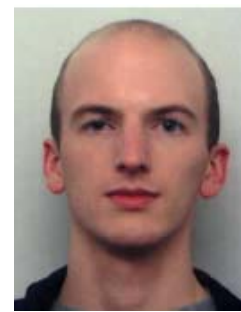

Hermen A. Toersche was born in WesterhaarVriezenveensewijk, the Netherlands in 1986. He received his M.Sc. degree from the University of Twente, Enschede, the Netherlands in 2010 at the Computer Architecture for Embedded Systems group, where he currently also is a Ph.D. candidate. His research interests include efficient distributed embedded systems.

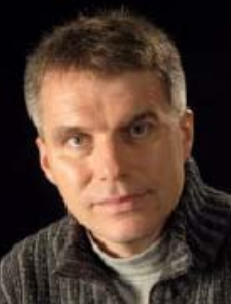

Johann L. Hurink received the Ph.D. degree from University of Osnabrueck (Germany) in 1992 for a thesis on a scheduling problem occurring in the area of public transport. From 1992 until 1998 he has been an assistant professor at the same university working on local search methods and complex scheduling problems. From 1998 until 2005 he has been an assistant professor and from 2005 until 2009 an associated professor in the group Discrete Mathematics and Mathematical Programming at the department of Applied Mathematics at the University of Twente. Since 2009 he is a full professor of the same group. Current work includes the application of optimization techniques and scheduling models to problems from logistics, health care and within Smart Grids.

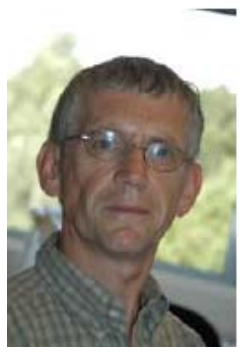

Gerard J.M. Smit received his M.Sc. degree in electrical engineering from the University of Twente. $\mathrm{He}$ then worked for four years in the research and development laboratory of Oc'e in Venlo. He finished his Ph.D. thesis entitled "the design of Central Switch communication systems for Multimedia Applications" in 1994. He has been a visiting researcher at the Computer Lab of the Cambridge University in 1994 and a visiting researcher at Lucent Technologies Bell Labs Innovations, New Jersey in 1998. Since 1999 he works in the Chameleon project, which investigates new hardware and software architectures for battery-powered hand-held computers. Currently his interests are: low-power communication, wireless multimedia communication, and reconfigurable architectures for energy reduction. Since 2006 he is full professor in the CAES chair (Computer Architectures for Embedded Systems) at the faculty EEMCS of the University of Twente. Prof. Smit has been and still is responsible of a number of research projects sponsored by the EC, industry and Dutch government in the field of multimedia and reconfigurable systems. 